\title{
RESEARCH
}

Open Access

\section{Degenerative findings in lumbar spine MRI: an inter-rater reliability study involving three raters}

\author{
Klaus Doktor ${ }^{1,2,3^{*}}$ (D), Tue Secher Jensen ${ }^{2,3,4}$, Henrik Wulff Christensen ${ }^{2}$, Ulrich Fredberg ${ }^{3,5}$, Morten Kindt ${ }^{3}$,
} Eleanor Boyle $e^{1}$ and Jan Hartvigsen ${ }^{1,2}$

\begin{abstract}
Background: For diagnostic procedures to be clinically useful, they must be reliable. The interpretation of lumbar spine MRI scans is subject to variability and there is a lack of studies where reliability of multiple degenerative pathologies are rated simultaneously. The objective of our study was to determine the inter-rater reliability of three independent raters evaluating degenerative pathologies seen with lumbar spine MRI.

Methods: Fifty-nine people, 35 patients with low back pain (LBP) or LBP and leg pain and 24 people without LBP or leg pain, received an MRI of the lumbar spine. Three raters (one radiologist and two chiropractors) evaluated the MRIs for the presence and severity of eight degenerative spinal pathologies using a standardized format: Spondylolisthesis, scoliosis, annular fissure, disc degeneration, disc contour, nerve root compromise, spinal stenosis and facet joint degeneration. Findings were identified and classified at disc level according to type and severity. Raters were instructed to evaluate all study sample persons once to assess inter-rater reliability (fully crossed design). Reliability was calculated using Gwet's Agreement Coefficients $\left(A C_{1}\right.$ and $A C_{2}$ ) and Cohen's Kappa ( $\mathrm{K}$ ) and Conger's extension of Cohen's. Gwet's probabilistic benchmarking method to the Landis and Koch scale was used. MRI-findings achieving substantial reliability was considered acceptable.
\end{abstract}

Results: Inter-rater reliability for all raters combined, ranged from (Gwet's $A C_{1}$ or $A C_{2}$ ): 0.64-0.99 and according to probabilistic benchmarking to the Landis and Koch scale equivalent to moderate to almost perfect reliability. Overall reliability level for individual pathologies was almost perfect reliability for spondylolisthesis, spinal stenosis, scoliosis and annular fissure, substantial for nerve root compromise and disc degeneration, and moderate for facet joint degeneration and disc contour.

Conclusion: Inter-rater reliability for 3 raters, evaluating 177 disc levels, was found to be overall acceptable for 6 out of 8 degenerative MRI-findings in the lumbar spine. Ratings of facet joint degeneration and disc contour achieved moderate reliability and was considered unacceptable.

Keywords: Agreement, Reliability, Reproducibility, Lumbar spine, Low Back pain, Leg pain, Sciatica, No-low back pain, Recumbent MRI, Supine MRI, MR, Magnetic resonance imaging

\footnotetext{
* Correspondence: k.doktor@nikkb.dk

${ }^{1}$ Department of Sport Sciences and Clinical Biomechanics, University of

Southern Denmark, Odense, Denmark

${ }^{2}$ Nordic Institute of Chiropractic and Clinical Biomechanics, Odense, Denmark

Full list of author information is available at the end of the article
}

(c) The Author(s). 2020 Open Access This article is distributed under the terms of the Creative Commons Attribution 4.0 International License (http://creativecommons.org/licenses/by/4.0/), which permits unrestricted use, distribution, and reproduction in any medium, provided you give appropriate credit to the original author(s) and the source, provide a link to the Creative Commons license, and indicate if changes were made. The Creative Commons Public Domain Dedication waiver (http://creativecommons.org/publicdomain/zero/1.0/) applies to the data made available in this article, unless otherwise stated. 
PACS picture, archiving and communication system (i.e. Agfa Impax) REDCap Research Electronic Data Capture program

\section{Background}

Imaging has been used in the diagnostic workup of people seeking care for low back pain for more than a hundred years. Consequently, conventional radiographs, computerized tomography (CT) or magnetic resonance imaging (MRI) is accepted, if not expected, by many patients and doctors [1-4]. For any diagnostic procedure including imaging to be useful, it must first demonstrate adequate reliability $[5,6]$.

Most people would claim that they understand and appreciate the meaning of agreement as well as the meaning of disagreement, and we all deal with the consequences of both every single day of our lives. In healthcare this is certainly the case and can have grave consequences for doctors and patients, since the quality of care and procedures delivered in health care systems around the world, depends on this seemingly simple notion. Patients are increasingly aware of different doctors having different opinions regarding their health issues. This variability may be due to variations in nomenclature $[7,8]$, and it is critical for radiologists and other interpreters of diagnostic imaging, such as chiropractors, to reduce interpreter variability [6]. Inter-rater reliability is an important parameter to measure and is of concern as data-sets should reflect variation in the study participants and not variation in the raters involved in the study. For valid results it is important that raters are updated and trained in the use of standardized protocols prior to the evaluation of MRI findings. Diagnostic classification systems for MRI have been proposed to address interpreter variability and in a systematic review the reliability of different nomenclature and grading systems for lumbar disc herniation and nerve root compression were compared, ranging from $\mathrm{k}=0.39-0.81$ [9], and representing quite a range in reliability despite limited to two degenerative conditions: Disc herniation and nerve root compromise. It is uncertain what kind of variability and reliability raters would produce if evaluating multiple degenerative pathologies simultaneously. Previous reliability studies of MRI findings of the lumbar spine have mainly reported on single findings or a specific grading scale of lumbar spine degenerative pathology, such as disc herniation $[10,11]$, spinal stenosis $[7,12]$ and end-plate changes [13]. However, a few studies have examined a handful of spinal degenerative pathologies simultaneously using various classification systems/scales [5, 8, 14, 15]. To our knowledge, there are few reliability studies on lumbar spine MRI findings that have both included raters of different professions and included multiple degenerative findings: One study compared medical radiologists, chiropractic radiologists and chiropractors [16]. Another study investigated reliability between a radiologist, a chiropractor and a second year resident of rheumatology in classifying degenerative MRI-findings of the cervical spine [17]. Thus, there is a need for studies investigating reliability for a wider range of spinal degenerative pathologies based on standardized formats and involving more than one profession participating in MRI readings in radiology departments.

\section{Objectives}

The objective of this study was to determine the interrater reliability of the evaluation of degenerative findings in lumbar spine MRI.

\section{Methods \\ Design}

Fully crossed inter-rater reliability study.

Guidelines for reporting reliability and agreement studies (GRRAS-guidelines) have been followed in this paper [18].

\section{Sample size calculation}

In a test for agreement between two raters using the Kappa statistic, a sample size of 51 subjects achieves $80 \%$ power to detect a true Kappa value of 0.70 in a test of HO: Kappa $=\kappa 0$ vs. H1: Kappa $\neq \kappa 0$, when there are 6 categories with frequencies equal to $0.48,0.28,0.20$, $0.03,0.01$, and 0.00 . This power calculation is based on a significance level of 0.05000 . Furthermore, we assumed the three disc-levels per participant to be independent, leaving us with 177 observations [19].

\section{Study population and reliability sample}

Fifty-nine MRIs of the lumbar spine from people with or without LBP, who were enrolled in a cross-sectional study, were included in this study from February 26th, 2018 to April 26th, 2018.

People with LBP or LBP and leg pain were invited to participate, when scheduled to the hospital for an MRI procedure, ordered by their primary care physician. The inclusion/exclusion criteria for people with LBP were: 1) Referred to Department of Radiology, Silkeborg Regional Hospital, Denmark for MRI from primary care (general practitioners or chiropractors) with LBP or LBP and leg pain; 2) Having symptoms for $>4$ weeks; 3) 18-60 years of age; 4) Not part of a referral pathway to spinal surgery or another secondary care sector activity 5) No suspicion of serious pathology, i.e. cancer, infection or inflammatory arthritis; 6) Able to stand up for at least $20 \mathrm{~min}$; 7) Able to read and write Danish.

The same criteria were used for people without LBP (no-LBP) with the exclusion of criteria 1) and 2). People in the no-LBP group were mainly recruited from a local 
school of nursing near the hospital, employees at the hospital and through announcements in workplace environments in Silkeborg Municipality/City, Denmark. Recruitment was carried out by posters and by personal communication.

Informed consent was provided by all participants via REDCap (Research Electronic Data Capture) installed on i-Pads. Recruitment for all participants was consecutive on a first come, first serve basis. A total of 242 people were initially included in the study population. Participants were assigned to subgroups based on self-reported symptoms/no-symptoms in their baseline questionnaires. Six people were excluded because of age over 60 years and 6 were excluded because of technical problems with their baseline questionnaires or failing to complete the MRI procedures. The remaining 230 individuals defined our main study population (see Fig. 1), and the first 59 individuals giving a fair representation of participants with LBP, leg pain and no-LBP in each group defined the reliability study sample.

\section{MRI-procedures}

All patients were scanned in either a Siemens Avanto 1.5 T or a Siemens Skyra $3 \mathrm{~T}$ MRI unit and all no-LBP individuals were scanned in an open MRI unit (Paramed OpenMR 0.5 T). MRI sequences for all three scanners were: Sagittal T1 and T2 as well as T2 axial at the three lowest lumbar levels. For the $1.5 \mathrm{~T}$ and $3 \mathrm{~T}$ systems, the sagittal T2 weighted sequence also included T2 fatsat (DIXON).

\section{Raters, training and consensus}

Rater 1, a medical radiologist consultant with 30 years of experience in musculoskeletal MRI; Rater 2, a chiropractor

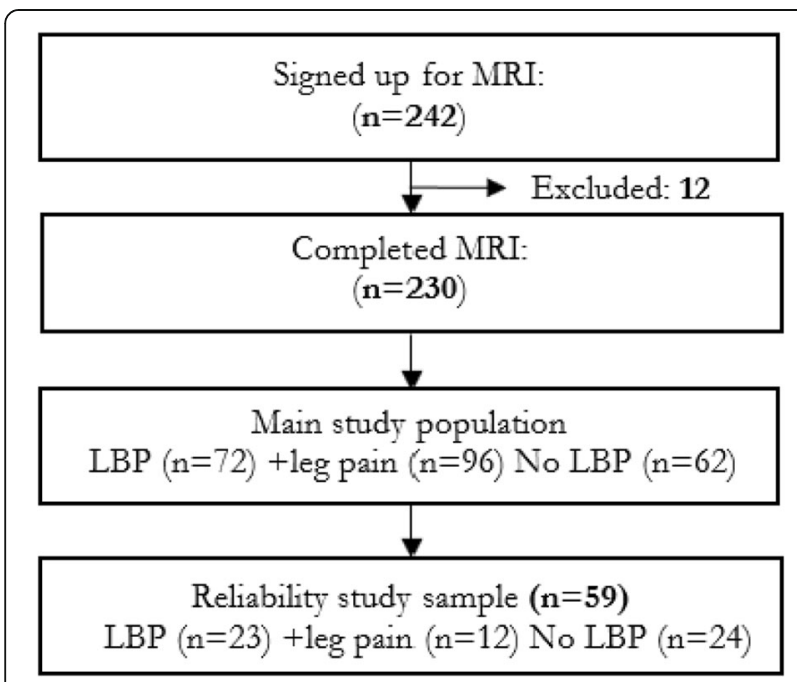

Fig. 1 Flowchart of selection of main study population and the reliability study sample and $\mathrm{PhD}$ student with 28 years of clinical and radiography experience and 4 years of MRI experience including over 1000 supervised reports of lumbar MRI in the same radiology department; Rater 3, a chiropractor and senior researcher with 12 years of clinical research and MRI experience from radiology departments. All raters had, in various degrees, experience with reliability of diagnostic classification model as well as clinical experience with spinal diagnostic imaging $[13,17,20,21]$.

To ensure consensus regarding understanding of the diagnostic classification, an evaluation manual was prepared based on existing literature [5, 22-29] (see Additional files 1 and 2). For the purpose of training and to identify practical issues in the evaluation process, all three raters independently analyzed and classified 10 MRIs based on the manual. The raters then met to compare ratings and discuss adjustments to the assessment and coding process. The evaluation manual was then adjusted, and a second set of 5 MRIs was rated, compared and discussed before the final version of the manual was prepared.

\section{MRI evaluation and classification of findings}

The three raters evaluated 177 disc levels (the three lowest lumbar levels: L3/L4 - L5/S1) for the presence of the following eight degenerative pathologies, independently: Spondylolisthesis; Scoliosis; Annular fissure; Disc degeneration; Disc contour; Nerve root compromise; Spinal stenosis; and Facet joint degeneration. The image findings were classified based on methods described in the literature (see Table 1).

The raters retrieved images in PACS (Picture, Archiving and Communication System: Agfa Impax, version 5.2) and filled in the standardized research evaluation form in REDCap. All images were assessed and analyzed on diagnostic Agfa Impax workstations with high resolution diagnostic monitors (Totoku Monochrome MS33I2_Pair, 3 mpx. Barco MDNC-2121 color pair, 2 mpx and Barco MDNC2121 monochrome pair, $2 \mathrm{mpx}$ ). The raters were blinded with respect to clinical information and previous report of findings.

\section{Data management and statistical analysis}

Data analysis was carried out in Stata, ver.15.1 (StataCorp LLC, 4905 Lakeway Drive, College Station, Texas 77,845, USA) and AgreeStat 2015.1 for Excel Windows/Mac (Advanced Analytics, LLC. PO Box 2696, Gaithersburg, MD 20886-2696, USA.).

Inter-rater reliability, based on 3 lower disc level of 59 persons $=177$ levels, was determined for binominal, nominal and ordinal data (see Table 1) by calculating percent agreement and chance-corrected agreement coefficients (Cohen's/Conger's $\mathrm{K}$ and Gwet's $\mathrm{AC}_{1}$ (unweighted) and $\mathrm{AC}_{2}$ (weighted)) for pair-wise raters and for the three raters overall [33], and were reported with $95 \%$ confidence 
Table 1 Classification of MRI findings

\begin{tabular}{lll}
\hline Diagnostic findings & Scale/categories & Definitions \\
\hline Spondylolisthesis, (Meyerding [27]) & Ordinal & $\begin{array}{l}\text { Defined as slippage of the vertebral body in relation to the one below in: } \\
\text { Anterior, posterior or lateral direction. }\end{array}$ \\
Grade I & 0 & Normal \\
Grade II & 1 & Displacement of vertebral body $\leq 1 / 4$ of vertebral body below. \\
Grade III & 2 & Displacement of vertebral body $\leq 1 / 2$ of vertebral body below. \\
Grade IV & 3 & Displacement of vertebral body $\leq 3 / 4$ of vertebral body below. \\
Disc degeneration, (Pfirrmann [22]) & 4 & Displacement of vertebral body $\leq 4 / 4$ of vertebral body below. \\
Grade I: & Ordinal & For this study grade I and II is considered normal. \\
& 0 & $\begin{array}{l}\text { Nucleus pulposus is homogenous and has high, bright white, signal } \\
\text { intensity. Clear distinction of nucleus and annulus. Normal heights of the }\end{array}$
\end{tabular}

Grade II: $\quad 0$

Grade III:

Grade IV: $\quad 2$

Grade V: $\quad 3$

Nerve root compromise, (Lee [24])

Normal

Ordinal

Contact and deviation 2

Compression 3

Spinal stenosis, (Lee [24]) O Ordinal

Central

No stenosis:

Relative stenosis:

Absolute stenosis: 2

Lateral

No stenosis: $\quad 0$

Relative stenosis:

Absolute stenosis:

Foraminal

No stenosis: $\quad 0$

Relative stenosis: $\quad 1$

Absolute stenosis: 2
Like grade I, but the nucleus pulposus is inhomogeneous, with or without clear horizontal bands.

Nucleus pulposus being inhomogeneous and gray, unclear distinction of the nucleus and annulus, intermediate signal intensity and normal to slightly decreased intervertebral disc height.

Inhomogeneous, gray to black nucleus pulposus and no distinction between the nucleus and the annulus. The signal intensity is intermediate to hypointense and normal to moderately decreased disc height.

Nucleus pulposus is inhomogeneous and black, with hypointense signal intensity and collapsed disk space.

No contact to nerve roots

Perineural fat obliteration from two opposing sides. No morphologic change (no signs of compression/deformation) of the nerve root.

Perineural fat obliteration surrounding the nerve root from four sides. No morphologic change (no compression/deformation) of nerve root.

Visible nerve root collapse or morphologic change

Up to $3 \mathrm{~mm}$ disc bulge is normal.

Reduced space $<50 \%$, but still visible fluid signal around the nerve roots.

$50 \%$ reduction or more of the dural sac area and no visible signal (dark/black) from cerebrospinal fluid around the nerve roots or medulla spinalis.

Normal levels of perineural fat.

Reduced space, perineural fat obliteration from at least two opposing sides but still visible perineural fat/CSF signal in the recess.

Reduction of the recess to a point where perineural fat signal/CSF signal no longer is visible.

Normal upside-down pear shape contour of the foramina with an apical nerve root location.

Reduced space, but still visible perineural fat signal in the foramen.

Reduction of the foramen to the point where perineural fat signal is no longer visible. 
Table 1 Classification of MRI findings (Continued)

\begin{tabular}{|c|c|c|}
\hline Diagnostic findings & Scale/categories & Definitions \\
\hline \multicolumn{3}{|l|}{ Facet degeneration, } \\
\hline (Ross/Moore [30]; Pathria [31]) & Ordinal & \\
\hline No degeneration: & 0 & Normal \\
\hline Mild degeneration: & 1 & Mild joint space narrowing and joint irregularity. \\
\hline Moderate degeneration: & 2 & $\begin{array}{l}\text { Moderate joint space narrowing/irregularity, subchondral sclerosis/ } \\
\text { osteophyte formation. }\end{array}$ \\
\hline Severe degeneration: & 3 & $\begin{array}{l}\text { Little, if any, joint space, severe subchondral sclerosis/ osteophyte } \\
\text { formation. Possible subluxation and/or subchondral cyst formation. }\end{array}$ \\
\hline Scoliosis (Cobb [29]) & Binominal & $\begin{array}{l}\text { Defined as any spinal curvature with a } \\
\text { Cobb's angle greater than } 10 \text { degrees. }\end{array}$ \\
\hline sinistro convex & $0 / 1$ & Apex of the curvature to the left. \\
\hline dextro convex & $0 / 1$ & Apex of the curvature to the right. \\
\hline rotational & $0 / 1$ & $\begin{array}{l}\text { Pedicles and spinous process oriented to } \\
\text { the left or right. }\end{array}$ \\
\hline Annular Fissure, (April [23]) & $\begin{array}{l}\text { Binominal } \\
0 / 1\end{array}$ & $\begin{array}{l}\text { High T2 signal }(\mathrm{HIZ}) \text { in the otherwise low signal annulus. } \\
\text { Diameter }>1.5 \mathrm{~mm} \text {. } \\
\text { Annulus material visible all around the fissure. }\end{array}$ \\
\hline Disc contour, (Fardon [32]) & Nominal & \\
\hline Normal or bulge & 0 & $\begin{array}{l}<3 \mathrm{~mm} \text { and }>25 \% \text { of the disc periphery ( } 90 \text { degrees). Negative for } \\
\text { herniation. }\end{array}$ \\
\hline Protrusion: & 1 & $\begin{array}{l}<25 \% \text { ( } 90 \text { degrees) of disc periphery, distance between disco-vertebral } \\
\text { corners is greater than distance of disc material past the base, } \\
\text { measured in same plane. }\end{array}$ \\
\hline Extrusion: & 2 & $\begin{array}{l}\text { Dimension of disc material in any one direction is greater than distance } \\
\text { between disco-vertebral corners. Migration cephalad or caudad } \\
\text { indicates extrusion. }\end{array}$ \\
\hline Sequestration: & 3 & Disc material has lost continuity with the parent disc. \\
\hline Combination of types & 4 & Combined protrusion and extrusion \\
\hline
\end{tabular}

intervals. Gwet's agreement coefficients, $\mathrm{AC}_{1}$ and $\mathrm{AC}_{2}$, were used to address the $\mathrm{K}$ paradox [34] and has been shown to be more stable and paradox-resistant than Cohen's $\mathrm{k}$ and other coefficients $[33,35]$. The $\mathrm{\kappa}$ paradoxes with very low or very high prevalence's are well described in the literature $[36,37]$. The first paradox occurs when percent chance agreement $\left(\mathrm{p}_{\mathrm{e}}\right)$, is large, the correction process can convert a relatively high value of observed agreement $\left(\mathrm{p}_{\mathrm{O}}\right)$ into a relatively low value of $\kappa$. The second paradox occurs when unbalanced marginal totals produce higher values of $\mathrm{k}$ than more balanced totals. In order to deal with the paradoxes (very low or very high prevalence's), we used Gwet's Agreement Coefficients $\left(\mathrm{AC}_{1}\right.$ and $\mathrm{AC}_{2}$ ). In order to compare our results with previous literature, we chose to also present both Cohen/Conger's $\kappa$ as well as the benchmarking procedure to the Landis and Koch scale [38]. The probabilistic method for benchmarking, as suggested by Gwet, is the absolute agreement and chance corrected agreement coefficients benchmarked as the cumulative probability (in our case exceeding 95\%) for the any coefficient to fall into one of the following intervals: < 0.00 "Poor"; 0.01 to 0.20 "Slight"; 0.21 to 0.40 "Fair";
0.41 to 0.60 "Moderate"; 0.61 to 0.80 "Substantial" and 0.81 to 1.00 "Almost Perfect" [39]. This method allows for a direct and more precise comparison of different agreement coefficients and their representation on the Landis and Koch scale (or any other scale used). Substantial reliability (0.61-0.80) was defined as acceptable for the purpose of this study and confidence intervals were presented with $95 \%$ certainty to include the true estimate. We recommend interested readers to follow the link in the reference list for more insight and comprehension of Gwet's Agreement Coefficents compared to other coefficients and the probabilistic benchmarking [40]. Key characteristics for the study target population and the study sample are presented for age, gender, symptoms, duration (see Table 2).

\section{Results}

The mean age is 42 years for the target population and 38 years for the reliability sample. Women represents 51 and $46 \%$ of the study target population and reliability sample respectably. LBP and leg pain patients account for 73 and 
Table 2 Characteristics of the study target population and study sample for reliability

\begin{tabular}{lll}
\hline Characteristics & Cross-sectional study population $(N=230)$ & $\begin{array}{l}\text { Reliability study sample } \\
\text { Inter-rater analysis }(n=59)\end{array}$ \\
\hline Age, in years, mean & $42.1($ SD 12.1) & $38.1(\mathrm{SD} 14.1)$ \\
Females, $\mathrm{n}(\%)$ & $118(51.1 \%)$ & $27(45.8 \%)$ \\
Patients, LBP, $\mathrm{n}(\%)$ & $72(31.3 \%)$ & $23(39.0 \%)$ \\
Patients, LBP + leg pain, $\mathrm{n}(\%)$ & $96(41.7 \%)$ & $12(20.3 \%)$ \\
Symptoms $>4$ wks., $\mathrm{n}(\%)$ & $168(73.0 \%)$ & $35(59.3 \%)$ \\
No LBP persons, $\mathrm{n}(\%)$ & $62(27.0 \%)$ & $24(40.7 \%)$
\end{tabular}

$59 \%$ respectably, all with symptoms over 4 weeks. No-LBP persons accounted for 27 and $41 \%$ respectively.

The prevalence of positive findings for all raters can be found in contingency tables in additional files. Generally, rater 1 had lower prevalence of diagnostic findings (average $=0.26$ ), compared to rater 2 (average $=0.40$ ) and rater 3 (average $=0.44$ ), with a total prevalence ranging from: $0.05-0.80$ for the individual MR-findings.

In Table 3, results for reliability at disc levels are presented. The overall reliability (raters 1,2 and 3) for the eight spinal degenerative pathologies ranged from moderate to almost perfect. Overall reliability level for individual pathologies was almost perfect for spondylolisthesis, spinal stenosis, scoliosis and annular fissure; substantial for nerve root compromise and disc degeneration; and moderate for facet joint degeneration and disc contour (prevalence of MRI-findings at disc levels can be found in Additional files 1 and 2 for ordinal and nominal scales respectively).

For the 3 rater pairs individually, the reliability ranged from moderate to almost perfect. For disc contour, there was a difference of one benchmark level between rater pairs, from moderate to substantial. There was no difference in benchmark levels between rater pairs for the remaining 7 pathologies.

The reliability among all 3 raters was moderate for facet joint degeneration and disc contour. Reliability for rater pairs $1-3$ and 2-3 was also moderate for disc contour.

There was almost perfect reliability and very little variability between rater pairs for spondylolisthesis, spinal stenosis, scoliosis and annular fissure. There was substantial reliability for disc degeneration and nerve root compromise. Variability was highest between rater-pairs for disc contour, but low for the other MRI findings.

\section{Discussion}

Inter-rater reliability for three rater-pairs was found overall acceptable for 6 of 8 degenerative MRI-findings of the lumbar spine. In addition, our results indicate that experienced chiropractors can achieve the same level of reliability as medical radiologists for MRI interpretations of spinal degenerative pathologies. Thus these classifications of findings are sufficiently comprehensible to be applied by experienced health care professionals and can be used for both quality assurance and research purposes.

Prior studies have investigated the reliability of identifying degenerative MRI-findings of the lumbar spine [38-41], but few are directly comparable to our study, because they investigated only one spinal degenerative pathology. Zoete et al. compared experienced medical and chiropractic radiologists reviewing MRI for lumbar spinal degenerative pathology [16]. The findings were dichotomized into a classification between "Specific findings" or "No specific findings", and higher reliability was found with more experienced raters. Specialists regardless of professional background obtained the best results (moderate reliability). Moll et al. investigated the reliability between a radiologist, a chiropractor and a second year resident of rheumatology, in classifying degenerative MRI-findings of the cervical spine and found overall substantial interrater reliability $(\kappa \geq 0.61)$ [17]. In our study, we achieved very low variability between the 3 raters and only one of eight pathologies had a difference in reliability among raters of one benchmark level indicating that experienced chiropractors and medical radiologists can achieve acceptable reliability in MRI interpretations, even when evaluating for a range of spinal degenerative pathologies in the lumbar spine.

Carrino et al. is one of few studies that has examined inter-rater agreement across several different spinal pathologies (spondylolisthesis, disc degeneration, endplate changes, annular fissure and facet degeneration) and including 111 cases [5]. Kappa values were generally modest and ranged for all raters overall from, $\mathrm{k}$ : $0.43-$ 0.66 (CI $0.27-0.70$ ), with only disc degeneration being of acceptable reliability, $\mathrm{\kappa}>0.60$. Average overall kappa among raters was, $\mathrm{K}=0.53$.

Another similar interrater agreement study involving 75 cases by $\mathrm{Fu}$ et al., included 10 degenerative spinal pathologies of the lumbar spine and reported absolute agreement and Fleiss $\mathrm{k}$, with $\mathrm{k}$-values being modest and with significant variability across degenerative conditions, ranging from $0.28-0.62$ (CI 0.27-0.64) [8]. Excluding transitional vertebrae $(\kappa=0.62)$, all 
Table 3 Inter-rater reliability coefficients and percent agreement with probabilistic benchmarking to the Landis and Koch scale in classification of MRI-findings at disc level

\begin{tabular}{|c|c|c|c|c|c|}
\hline \multirow[t]{2}{*}{$\begin{array}{l}\text { Diagnostic finding } \\
N=177 \text { disc levels }\end{array}$} & $\begin{array}{l}\text { Reliability } \\
\text { Rater } 1 \text { vs. } 2\end{array}$ & $\begin{array}{l}\text { Reliability } \\
\text { Rater } 1 \text { vs. } 3\end{array}$ & $\begin{array}{l}\text { Reliability } \\
\text { Rater } 2 \text { vs. } 3\end{array}$ & \multirow[t]{2}{*}{ All } & \multirow{2}{*}{$\begin{array}{l}\text { Landis and } \\
\text { Koch scale } \\
\text { Probabilistic } \\
\text { benchmark }\end{array}$} \\
\hline & 95\% C.I. & 95\% C.I. & 95\% C.I. & & \\
\hline \multicolumn{6}{|l|}{ Spondylolisthesis } \\
\hline Conger's $\mathrm{K}$ & $0.24[-0.16: 0.64]$ & $0.36[-0.01: 0.72]$ & $0.36[-0.01: 0.72]$ & 0.33 & Slight \\
\hline Gwet's $A C_{2}$ & 0.998 [0.997:1.000] & 0.998 [0.996:0.999] & 0.998 [0.996:0.999] & 0.99 & Almost perfect \\
\hline \%-agreement & 0.998 [0.997:1.000] & 0.998 [0.996:0.999] & 0.998 [0.996:0.999] & 0.99 & Almost perfect \\
\hline \multicolumn{6}{|l|}{ Disc degeneration } \\
\hline Conger's K & $0.60[0.51: 0.70]$ & $0.67[0.58: 0.76]$ & $0.76[0.69: 0.82]$ & 0.68 & Moderate \\
\hline Gwet's $A C_{2}$ & 0.90 [0.87:0.94] & 0.89 [0.85:0.93] & 0.91 [0.88:0.95] & 0.90 & Substantial \\
\hline \%-agreement & 0.95 [0.93:0.96] & 0.94 [0.93:0.96] & 0.96 [0.95:0.97] & 0.95 & Substantial \\
\hline \multicolumn{6}{|l|}{ Nerve compromise } \\
\hline Conger's K & $0.55[0.38: 0.71]$ & $0.56[0.39: 0.72]$ & $0.52[0.34: 0.70]$ & 0.54 & Fair \\
\hline Gwet's $A C_{2}$ & 0.96 [0.93:0.98] & $0.93[0.90: 0.96]$ & 0.92 [0.89:0.96] & 0.93 & Substantial \\
\hline$\%$-agreement & 0.96 [0.95:0.98] & 0.95 [0.93-0.97] & 0.94 [0.92:0.97] & 0.95 & Substantial \\
\hline \multicolumn{6}{|l|}{ Spinal stenosis } \\
\hline Conger's K & 0.19 [0.08:0.29] & $0.33[0.22: 0.45]$ & $0.43[0.34: 0.53]$ & 0.33 & Fair \\
\hline Gwet's $A C_{2}$ & 0.98 [0.97:0.98] & 0.98 [0.98:0.99] & 0.98 [0.97:0.98] & 0.98 & Almost perfect \\
\hline \%-agreement & 0.98 [0.98:0.99] & 0.99 [0.98:0.99] & 0.98 [0.98:0.99] & 0.98 & Almost perfec \\
\hline \multicolumn{6}{|l|}{ Facet degeneration } \\
\hline Conger's K & $0.27[0.16: 0.38]$ & $0.32[0.21: 0.42]$ & $0.35[0.25: 0.46]$ & 0.32 & Slight \\
\hline Gwet's $A C_{2}$ & 0.79 [0.74:0.84] & $0.79[0.74: 0.84]$ & $0.76[0.71: 0.82]$ & 0.78 & Moderate \\
\hline \%-agreement & 0.88 [0.86:0.90] & 0.89 [0.86-0.91] & 0.87 [0.85:0.90] & 0.88 & Moderate \\
\hline \multicolumn{6}{|l|}{ Scoliosis } \\
\hline Cohen's K & 0.49 [0.06:0.92] & 0.59 [0.22:0.96] & $0.75[0.40: 1.00]$ & 0.61 & Fair \\
\hline Gwet's $A C_{1}$ & 0.98 [0.96:1.00] & 0.98 [0.96:1.00] & 0.99 [0.97:1.00] & 0.98 & Almost perfect \\
\hline \%-agreement & 0.98 [0.96:1.00] & 0.98 [0.96:1.00] & 0.99 [0.97:1.00] & 0.98 & Almost perfec \\
\hline \multicolumn{6}{|l|}{ Annular Fissure } \\
\hline Cohen's K & 0.50 [0.32:0.68] & $0.45[0.26: 0.65]$ & $0.61[0.45: 0.77]$ & 0.53 & Moderate \\
\hline Gwet's $A C_{1}$ & 0.87 [0.82:0.93] & 0.88 [0.82:0.93] & 0.88 [0.83:0.93] & 0.88 & Almost perfect \\
\hline \%-agreement & 0.88 [0.83:0.93] & 0.88 [0.83:0.93] & 0.89 [0.84:0.93] & 0.88 & Almost perfect \\
\hline \multicolumn{6}{|l|}{ Disc contour } \\
\hline Cohen's K & $0.36[0.25: 0.48]$ & 0.27 [0.17:0.38] & 0.39 [0.29:0.49] & 0.34 & Fair \\
\hline Gwet's $A C_{1}$ & 0.73 [0.65:0.80] & 0.59 [0.50:0.68] & $0.62[0.53: 0.70]$ & 0.64 & Moderate \\
\hline \%-agreement & 0.75 [0.69:0.82] & $0.64[0.57: 0.71]$ & $0.67[0.60: 0.74]$ & 0.69 & Substantial \\
\hline
\end{tabular}

Inter-rater reliability using Gwet's $\mathrm{AC}_{1}$ (binominal/nominal data) and $\mathrm{AC}_{2}$ (ordinal data) and percent agreement are presented For comparison Cohen's K (binominal/nominal data) and Conger's K (ordinal data) also presented Numbers in parentheses are $95 \%$ confidence intervals $[95 \% \mathrm{Cl}]$

remaining 9 degenerative conditions in this study achieved unacceptable reliability, $\mathrm{k}<0.60$. The overall average kappa coefficient among all 4 raters was $\mathrm{\kappa}=$ 0.43 .

Absolute agreement and agreement coefficients in our study were similar or higher compared with Carrino et al., and generally higher compared with $\mathrm{Fu}$ et al. We achieved average overall $\kappa=0.59$ among all 3 raters. Both studies had interdisciplinary representation of raters and provided training and evaluation manuals, but also based reliability measures on less robust kappa-statistics, so their result might have proved better than ours, if the method proposed by Gwet had been used. 


\section{Methodical considerations}

When a reliability study is based on samples smaller than the study population, there may be loss of information. All persons in this study were consecutively selected and had the same chance of inclusion in the interrater-analysis. There was fair resemblance between the study population and the study sample, helping to reduce sampling error.

Only few studies have examined agreement across several different spinal pathologies in the lumbar spine and with modest levels of reliability and high variability across pathologies (Fleiss $\mathrm{k}$ and others). We achieved acceptable reliability for most degenerative pathologies ranging from: Gwet's AC $=0.31-0.99$.

In our study the raters were not selected randomly and only three specific raters were part of the analysis. In this study standard errors and confidence intervals of the study sample were based on fixed raters and consequently the inference generalizes and measures precision with respect to the universe of study persons only (with our inclusion criteria) and not the universe of raters, meaning its validity is limited to this specific group of raters that participated in the reliability experiment. This study indicated that even when raters have training materials or evaluation manuals available and use robust statistics, it is challenging to reach acceptable reliability for all degenerative pathologies.

We included no-LBP persons in our study sample for reliability, to resample the study population characteristics. This exposed us to the kappa paradoxes and made it difficult for us to compare our results directly to studies, where no-LBP persons were not included. But more importantly it challenged us to test the performance of several agreement coefficients, looking for more robust alternatives to Cohen's and Conger's extension of Cohen's $\kappa$. Gwet's $\mathrm{AC}_{1}$ and $\mathrm{AC}_{2}$ proved to be a good alternative. All no-LBP persons received supine MRI procedures in a new $0.5 \mathrm{~T}$ open MRI unit. This made it possible for raters to identify noLBP persons, since the image quality was lower and certain sequences were used specifically for the $0.5 \mathrm{~T}$ unit. For the $1.5 \mathrm{~T}$ and $3 \mathrm{~T}$ systems, the sagittal $\mathrm{T} 2$ weighted sequence also included T2 fatsat (DIXON). It is possibly a source for bias of the raters to rate fewer findings in this group.

In this study the pair-wise comparison revealed that experienced chiropractors generally achieved the same levels of reliability as the medical radiologist. It is uncertain whether the lower average prevalence of positive findings, as reported by the radiologist, is due to underestimation or overestimation of the MRI-findings on part of the radiologist/chiropractors respectively. The chiropractors had similar reports of prevalence of positive finding, maybe due to the fact that they had collected the evidence and authored most of the evaluation guide. All raters had previous experience with reliability studies, but a high level of agreement among raters on negative findings has helped maintain acceptable reliability for most diagnostic findings in this study.

\section{Clinical and research implications}

Reliability is an issue of concern, since it is of fundamental importance for the quality of health care, that raters or doctors can replicate and agree on their findings and conclusions [41]. In all health care disciplines doctors, researchers and others are working, at some level, with the concept of agreement and striving systematically to investigate healthcare procedures for their reliability and validity. Inter-rater reliability is an important parameter to measure and a concern as data-sets should reflect the study participants and not the raters involved in the study. For valid results it is important that raters are updated and trained in the use of standardized protocols prior to the evaluation of MRI findings. In this study two raters reported similar prevalence of positive findings, most likely due to more knowledge of the evaluation manual. More interdisciplinary reviews are needed to establish internationally recognized standards for degenerative spinal pathologies.

\section{Conclusion and recommendations}

Inter-rater reliability for three rater-pairs was found overall acceptable for 6 of 8 degenerative MRI-findings of the lumbar spine. The two chiropractors in the study achieved similar levels of reliability as the medical radiologist for MRI interpretations of spinal degenerative pathologies. The classifications of findings are for most degenerative pathologies sufficiently comprehensible to be applied by health care professionals and can be used for both quality assurance and further research purposes. A few adjustments to the rating protocol will be required to bring all pathologies to an acceptable level of reliability.

\section{Supplementary information}

Supplementary information accompanies this paper at https://doi.org/10. 1186/s12998-020-0297-0.

Additional file 1. Prevalence of findings at disc level (ordinal)

Additional file 2. Prevalence of findings at disc level (nominal)

\section{Abbreviations \\ $A C_{1}$ : Agreement Coefficient (unweighted); $A_{2}$ : Agreement Coefficient (weighted); CSF: Cerebrospinal Fluid; CT: Computerized Tomography; LBP: Low Back Pain; MRI: Magnetic Resonance Imaging}

\section{Acknowledgements}

The authors would like to acknowledge funding from the Foundation for Chiropractic and Clinical Biomechanics. The authors would also like to thank radiographers and others participating in organization of the project:

Annette Kryger Jensen, Jonas Knudsen, Birgitte Hornbæk Korsholm, Maria Jendritska Randlev, Brian Højgaard, Hanne la Cour Ginnerup, Diagnostic Centre, Silkeborg Regional Hospital. Orla Lund Nielsen, Nordic Institute for Chiropractic and Clinical Biomechanics, for support in data handling and Sara Lisa Doktor for proofreading the manuscript. 


\section{Authors' contributions}

$J H, T S J, K D$ participated in all parts of the preparation of this paper. HWC contributed with planning, text and advice and edited the final draft. UF participated in the planning and conceptualization of methods used at Diagnostic Centre, Silkeborg. MK advised and helped in defining the variable definitions for MRI findings based on the literature and was a rater in our study. EB provided statistical support. All authors proofread and approved this paper for publication.

\section{Funding}

Funding was provided from the Foundation for Chiropractic and Clinical Biomechanics in Denmark.

\section{Availability of data and materials}

The datasets used and/or analyzed during the current study are available from the corresponding author on reasonable request.

\section{Ethics approval and consent to participate}

All participants provided written informed consent. Approval by the local ethical committee was not needed due to the study's methodological nature. A letter of exemption from Regional Committee on Health Research Ethics is available from the author on request (case no. 48336). According to journal number 2015414037 the Danish Data Protection Agency has approved the project.

\section{Consent for publication}

Not applicable.

\section{Competing interests}

The authors declare that they have no competing interests.

\section{Author details}

'Department of Sport Sciences and Clinical Biomechanics, University of Southern Denmark, Odense, Denmark. ${ }^{2}$ Nordic Institute of Chiropractic and Clinical Biomechanics, Odense, Denmark. ${ }^{3}$ Diagnostic Centre, University Research Clinic for Innovative Patient Pathways, Silkeborg Regional Hospital, Aarhus University, Odense, Denmark. ${ }^{4}$ Department of Clinical Medicine, Aarhus University, Odense, Denmark. ${ }^{5}$ The Rheumatology Research Unit, Odense University Hospital, University of Southern Denmark, Odense, Denmark.

Received: 9 October 2019 Accepted: 9 January 2020

\section{Published online: 11 February 2020}

\section{References}

1. Cascade PN, Webster EW, Kazerooni EA. Ineffective use of radiology: the hidden cost. AJR Am J Roentgenol. 1998;170(3):561-4.

2. Deyo RA, Diehl AK, Rosenthal M. Reducing roentgenography use. Can patient expectations be altered? Arch Intern Med. 1987:147(1):141-5.

3. A multicentre audit of hospital referral for radiological investigation in England and Wales. Royal College of Radiologists Working Party. BMJ (Clinical research ed). 1991;303(6806):809-12.

4. Chou R, Deyo RA, Jarvik JG. Appropriate use of lumbar imaging for evaluation of low back pain. Radiol Clin N Am. 2012;50(4):569-85.

5. Carrino JA, Lurie JD, Tosteson AN, Tosteson TD, Carragee EJ, Kaiser J, et al. Lumbar spine: reliability of MR imaging findings. Radiology. 2009;250(1):161-70.

6. Jarvik JG, Deyo RA. Moderate versus mediocre: the reliability of spine MR data interpretations. Radiology. 2009;250(1):15-7.

7. Speciale AC, Pietrobon R, Urban CW, Richardson WJ, Helms CA, Major N, et al. Observer variability in assessing lumbar spinal stenosis severity on magnetic resonance imaging and its relation to cross-sectional spinal canal area. Spine (Phila Pa 1976). 2002;27(10):1082-6.

8. Fu MC, Buerba RA, Long WD 3rd, Blizzard DJ, Lischuk AW, Haims AH, et al. Interrater and intrarater agreements of magnetic resonance imaging findings in the lumbar spine: significant variability across degenerative conditions. Spine J. 2014;14(10):2442-8.

9. Li Y, Fredrickson V, Resnick DK. How should we grade lumbar disc herniation and nerve root compression? A systematic review. Clin Orthop Relat Res. 2015;473(6):1896-902.

10. van Rijn JC, Klemetso N, Reitsma JB, Majoie CB, Hulsmans FJ, Peul WC, et al. Observer variation in MRl evaluation of patients suspected of lumbar disk herniation. AJR Am J Roentgenol. 2005;184(1):299-303.
11. Lurie JD, Tosteson AN, Tosteson TD, Carragee E, Carrino JA, Kaiser J, et al. Reliability of magnetic resonance imaging readings for lumbar disc herniation in the spine patient outcomes research trial (SPORT). Spine (Phila Pa 1976). 2008:33(9):991-8.

12. Lurie JD, Tosteson AN, Tosteson TD, Carragee E, Carrino JA, Kaiser J, et al. Reliability of readings of magnetic resonance imaging features of lumbar spinal stenosis. Spine (Phila Pa 1976). 2008;33(14):1605-10.

13. Jensen TS, Sorensen JS, Kjaer P. Intra- and interobserver reproducibility of vertebral endplate signal (modic) changes in the lumbar spine: the Nordic Modic consensus group classification. Acta Radiol. 2007;48(7):748-54.

14. Kovacs FM, Royuela A, Jensen TS, Estremera A, Amengual G, Muriel A, et al. Agreement in the interpretation of magnetic resonance images of the lumbar spine. Acta Radiol. 2009:50(5):497-506.

15. Mulconrey DS, Knight RQ, Bramble JD, Paknikar S, Harty PA. Interobserver reliability in the interpretation of diagnostic lumbar MRI and nuclear imaging. Spine J. 2006;6(2):177-84.

16. de Zoete A, Ostelo R, Knol DL, Algra PR, Wilmink JT, van Tulder MW, et al. Diagnostic accuracy of lumbosacral spine magnetic resonance image Reading by chiropractors, chiropractic radiologists, and medical radiologists. Spine (Phila Pa 1976). 2015;40(11):E653-60.

17. Moll LT, Kindt MW, Stapelfeldt CM, Jensen TS. Degenerative findings on MRI of the cervical spine: an inter- and intra-rater reliability study. Chiropr Man Therap. 2018:26:43.

18. Kottner J, Audige L, Brorson S, Donner A, Gajewski BJ, Hrobjartsson A, et al. Guidelines for reporting reliability and agreement studies (GRRAS) were proposed. J Clin Epidemiol. 2011;64(1):96-106

19. Flack VF, Afifi AA, Lachenbruch PA, Schouten HJA. Sample Size Determinations for the Two Rater Kappa Statistic. Psychometrika. 1988;53(3): 321-5. https://doi.org/10.1007/BF0229421520.

20. Doktor K, Vilholm ML, Hardardottir A, Christensen HW, Lauritsen J. European guidelines on quality criteria for diagnostic radiographic images of the lumbar spine - an intra- and inter-observer reproducibility study. Chiropr Man Therap. 2019;27:20.

21. Masharawi Y, Kjaer P. Bendix T, Manniche C, Wedderkopp N, Sorensen JS, et al. The reproducibility of quantitative measurements in lumbar magnetic resonance imaging of children from the general population. Spine (Phila Pa 1976). 2008;33(19):2094-100

22. Pfirrmann CW, Metzdorf A, Zanetti M, Hodler J, Boos N. Magnetic resonance classification of lumbar intervertebral disc degeneration. Spine (Phila Pa 1976). 2001;26(17):1873-8.

23. Aprill C, Bogduk N. High-intensity zone: a diagnostic sign of painful lumbar disc on magnetic resonance imaging. Br J Radiol. 1992; 65(773):361-9.

24. Lee S, Lee JW, Yeom JS, Kim KJ, Kim HJ, Chung SK, et al. A practical MRI grading system for lumbar foraminal stenosis. AJR Am J Roentgenol. 2010; 194(4):1095-8.

25. Wildermuth S, Zanetti M, Duewell S, Schmid MR, Romanowski B, Benini A, et al. Lumbar spine: quantitative and qualitative assessment of positional (upright flexion and extension) MR imaging and myelography. Radiology. 1998;207(2):391-8

26. Modic MT, Masaryk TJ, Ross JS, Carter JR. Imaging of degenerative disk disease. Radiology. 1988;168(1):177-86.

27. Meyerding HW. Spondylolisthesis; surgical fusion of lumbosacral portion of spinal column and interarticular facets; use of autogenous bone grafts for relief of disabling backache. J Int Coll Surg. 1956;26(5 Part 1):566-91.

28. Goldstein LA, Waugh TR. Classification and terminology of scoliosis. Clin Orthop Relat Res. 1973:93:10-22.

29. Cobb JR. Scoliosis; quo vadis. J Bone Joint Surg Am. 1958;40-A(3):507-10.

30. Ross JS, Moore KR. Diagnostic imaging spine, 3rd edition. In: Philadelphia. 3rd ed. USA: Elsevier; 2015. p. PA 19103-2899.

31. Pathria M. Imaging of spine instability. Semin Musculoskelet Radiol. 2005; 9(1):88-99.

32. Devereux G, Steele $\mathrm{S}$, Jagelman T, Fielding S, Muirhead R, Brady J, et al. An observational study of matrix metalloproteinase (MMP)-9 in cystic fibrosis. J Cyst Fibros. 2014;13(5):557-63.

33. Gwet KL. Handbook of inter-rater reliability - the definitive guide to measuring the extent of agreement among raters/ by Kilem Li Gwet - 4th ed. Gaithersburg, MD 20886-2696. United States of America: Advanced Analytics, LLC; 2014

34. Uebersax J. Kappa coefficients: A critical appraisal 2002 [Available from: https://www.john-uebersax.com/stat/kappa.htm (November 21, 2019). 
35. Wongpakaran N, Wongpakaran T, Wedding D, Gwet KL. A comparison of Cohen's kappa and Gwet's AC1 when calculating inter-rater reliability coefficients: a study conducted with personality disorder samples. BMC Med Res Methodol. 2013;13:61.

36. Feinstein AR, Cicchetti DV. High agreement but low kappa: I. the problems of two paradoxes. J Clin Epidemiol. 1990;43(6):543-9.

37. Cicchetti DV, Feinstein AR. High agreement but low kappa: II. Resolving the paradoxes. J Clin Epidemiol. 1990;43(6):551-8.

38. Conger AJ. Integration and generalization of Kappas for multiple raters. Psychol Bull. 1980;88:322-8.

39. Landis JR, Koch GG. An application of hierarchical kappa-type statistics in the assessment of majority agreement among multiple observers. Biometrics. 1977;33(2):363-74.

40. Gwet KL. Benchmarking Agreement Coefficients 2014 [Available from: https://inter-rater-reliability.blogspot.com/2014/12/benchmarkingagreement-coefficients.html\#comment-form [12-09-2019 10:56:30].

41. Herzog R, Elgort DR, Flanders AE, Moley PJ. Variability in diagnostic error rates of $10 \mathrm{MRI}$ centers performing lumbar spine MRI examinations on the same patient within a 3-week period. Spine J. 2017;17(4):554-61.

\section{Publisher's Note}

Springer Nature remains neutral with regard to jurisdictional claims in published maps and institutional affiliations.

Ready to submit your research? Choose BMC and benefit from:

- fast, convenient online submission

- thorough peer review by experienced researchers in your field

- rapid publication on acceptance

- support for research data, including large and complex data types

- gold Open Access which fosters wider collaboration and increased citations

- maximum visibility for your research: over $100 \mathrm{M}$ website views per year

At BMC, research is always in progress.

Learn more biomedcentral.com/submissions 